\title{
O ORDENAMENTO JURÍDICO NO CONSTITUCIONALISMO BRASILEIRO: PERPLEXIDADES CONCERNENTES AO DIREITO CIVIL
}

\section{LEGAL SYSTEM IN BRAZILIAN CONSTITUTIONALISM: PERPLEXITIES REFERRING TO CIVIL LAW}

\author{
Hamilton da Cunha Iribure Júnior \\ Doutor em Direito pela Pontifícia Universidade Católia de São Paulo. Atualmente é \\ professor na graduação e pós graduação "stricto sensu" pela Faculdade de Direito do Sul \\ de Minas. E-mail: hamilton.adv@terra.com.br \\ Henrique Cassalho Guimarães \\ Mestrando em direito pela Faculdade de Direito do Sul de Minas. \\ E-mail: henrique_cguimaraes@hotmail.com
}

Recebido em: 22/08/2016

Aprovado em: 09/02/2017

Doi: $10.5585 /$ rdb.v17i7.466

RESUMO: O constitucionalismo contemporâneo delineia uma nova forma de se conceber e interpretar o ordenamento jurídico, prezando pela aproximação do direito à sociedade e da sociedade ao direito de modo tendente a emancipar o indivíduo no plano fático. Consectário disso é a repercussão do propósito de humanização intrínseco na Constituição da República Federativa do Brasil de 1988 no direito civil, a ponto de o colocar sob um novo eixo. Tal relacionamento, entretanto, envolve vários aspectos que não podem ser negligenciados, como a adequação do liame entre uma concepção ordenamental do direito e o constitucionalismo. Eis o principal objetivo deste artigo: analisar os reflexos desta relação no âmbito do direito civil brasileiro, assim como a necessidade de determinadas correções de rota na busca de uma maior efetividade social do direito. Utiliza-se, para tanto, o método analítico e a técnica bibliográfica. A partir desta metodologia se indica encaminhamentos para a superação de algumas perplexidades advindas da constitucionalização do direito civil.

Palavras-Chave: Ordenamento. Constitucionalismo. Dogmática. Civil.

\begin{abstract}
The contemporaneous constitutionalism outlines a new manner to conceive and interpret the legal system, considering the alignment of law with society and society with law in order to emancipate the individual in the factual level. This results in the repercussion of humanization purpose in the Constitution of Federative Republic of Brazil of 1988 in civil law, to the extent of approaching it under a new perspective. However, such relationship involves several aspects which cannot be neglected, such as adequacy of Liame as a conception of legal system and constitutionalism. This article primarily aims at: analyzing the effects of this relation pursuant to Brazilian civil law, as well as the need of certain corrections in order to search for greater social effectiveness of law. For this purpose, an analytical method and bibliography technique are used. From this methodology, alternatives are indicated to overcome some perplexities arising from constitutionalisation of civil law.
\end{abstract}

Keywords: System. Constitutionalism. Dogmatics. Civil. 
SUMÁRIO: Introdução. 1. A dogmática jusprivatista: escorço teórico. 2. O direito civil e o constitucionalismo. 3. Perplexidades, veredas e oportunidades. Conclusão. Referências Bibliográficas.

\section{INTRODUÇÃO}

O ordenamento jurídico se revestiu de variadas feições ao longo do tempo. A relação entre direito e Estado que hoje nos é tão natural, importa sublinhar, não passa de uma episteme, uma perspectiva moderna - dentre outras concepções - ordenamental do direito. Com o constitucionalismo contemporâneo novos ares permeiam este relacionamento, sendo oferecida uma forma de se conceber e interpretar a ordem jurídica voltada, como nunca antes, à realização social do direito e à emancipação do indivíduo. Uma mudança paradigmática, entretanto, nunca é simples.

Sob uma ótica racional-sistemática do ordenamento jurídico, que é tão usual na corrente tradição acadêmica e jurisdicional, é possível afirmar que o constitucionalismo brasileiro contemporâneo gerou radicais mudanças sobre o direito civil ao erigir a Constituição da República Federativa do Brasil de 1988 no ápice da ordem jurídica e ao projetá-la como substrato de legitimidade do direito. Mas, para além de uma visão hierarquizada do ordenamento jurídico, possível também é conceber o movimento de constitucionalização do direito privado a partir de outras perspectivas.

Questionar alguns dos reflexos do constitucionalismo no direito civil e aquilo que se deseja do direito contemporâneo é o escopo central do presente artigo. A partir do método analítico e da técnica bibliográfica, tenciona-se analisar possíveis vertentes do relacionamento entre ordenamento jurídico e constitucionalismo, bem como examinar seus efeitos sobre o campo da civilística e do sistema de direitos fundamentais aplicáveis no âmbito privado. Trata-se de um olhar teórico que cuida de não subverter a prática judicial.

Para tanto, pretende-se descrever, inicialmente, mediante uma análise histórico-jurídica, o influxo da dogmática na ciência do direito e na sociedade. Ainda que se compreenda que as mudanças históricas e jurídicas não se dão de forma linear e homogênea, objetiva-se tecer uma narrativa lógica de momentos que possibilitem destacar os principais traços das diversas fases da dogmática jurídica. Interessante perspectiva de análise, nesse instante, é a que inter-relaciona a ciência do direito e a operacionalidade do direito, assim como a que releva os interesses subjacentes à norma jurídica.

Posteriormente, o objeto de análise recai sobre a aproximação entre o direito civil e o constitucionalismo no Brasil. Embora com necessária brevidade, busca-se evidenciar o grau de influência da Constituição do Brasil - e dos direitos fundamentais - na seara do direito civil, assim como as variações hermenêuticas sobre a eficácia da norma constitucional no campo privado, tanto no plano teórico quanto na prática forense, mormente no âmbito Supremo Tribunal Federal.

No momento subsequente, são propostos pontos de reflexão sobre o modelo técnico operativo do direito civil ante o constitucionalismo. Sem a pretensão de fornecer respostas ou conclusões apodíticas, o escopo nesta etapa é explicitar perplexidades e descortinar potenciais encaminhamentos em prol de um direito civil constitucionalizado socialmente salutar. Imprescindível se faz - e esta é a premissa da qual se parte - pensar na melhor forma de compreender o direito e a dogmática à luz dos anseios sociais contemporâneos. 


\section{A DOGMÁTICA JUSPRIVATISTA: ESCORÇO TEÓRICO}

A modernidade política e jurídica pós-Revolução Francesa, inspirada pelo racionalismo iluminista, se faz com o emergir de um Estado regido pelo paradigma da unidade e um ordenamento pretensiosamente completo. A descontinuidade com a ordem jurídica pregressa, entretanto, teve seu preço. Visando a um ordenamento monolítico, contemplador de toda manifestação em sociedade, o Estado despojou de seus ombros o pesado manto da complexidade social (GROSSI, 2010, p. 45).

Dentre as diversas consequências advindas desta postura, sobressaem-se duas: internamente, a projeção de uma extraordinária compactação, que, invariavelmente, resultou em uma absoluta simplificação dos fenômenos sociais (absolutismo jurídico); externamente, o Estado projetou-se como uma perfeita insularidade, superior e independente à sociedade e suas complexas relações.

Esta mácula marcou o movimento moderno de ordenação e codificação. Tal como um refluxo do fundamento metafísico do Estado absolutista, tinha-se a crença em uma doutrina da neutralidade axiológica do saber, em um conhecimento objetivo, metodologicamente puro, baseado na observação causal dos fenômenos, livre de juízos de valor ou ideologias, à parte da moral, isento de prenoções e preconceitos (LÖWY, 2000, p. 17). Neste contexto de ruptura, o discurso proclamado é o de que a vontade régia (absolutismo) foi suplantada pela vontade do povo (contratualismo), exteriorizada por meio da lei.

Em meio a este artificialismo, o direito passa a ser engendrado e validado pelo Estado, abstração representativa da vontade do povo. Aliado à hermenêutica exegética, os códigos tornaram-se dogmas. O Code Civil Napoleônico de 1804, precursor do movimento europeu de codificação, simboliza bem o que foi exposto e, em seu afã de abarcar a totalidade das relações jurídicas em sociedade, reduzia o direito à lei (legalismo), fazendo uma verdadeira clivagem entre o direito - prescrito em lei - e o não-direito - sem previsão legal ${ }^{1}$.

Mirando a vinculação do jurista a pressupostos conceituais seguros - hábeis a serem sustentados por princípios indiferentes às contingências do tempo, eficientes e duradouros -, à dogmática jurídica foi atribuído um papel de realce. Como consectário, o ordenamento jurídicoprivado, em sua acepção moderna, vem a se estabilizar como uma negação do condicionamento histórico-social do direito, operando mediante uma abstração das normas jurídicas ${ }^{2}$ (método técnico lógico-abstrato). Ainda, é rompida a salutar inter-relação entre direito e sociedade ${ }^{3}$.

Em detrimento de uma carga axiológica atribuível ao sujeito de direito, tal ordenamento jurídico é voltado a um sujeito virtual, abstrato, despido de valores e aspirações. O Código Civil era considerado a "Constituição" deste sujeito privado sem rosto, sendo incumbido de regular a integralidade das relações cíveis. Em paralelo, sob a égide de uma relação dicotômica entre o público e o privado, a Carta constitucional assegurava prioritariamente direitos negativos ao indivíduo contra o Estado, sendo impensável na época a defesa de direitos e garantias individuais constitucionais oponíveis nas relações privadas. Neste contexto liberal de primazia do patrimônio sobre o indivíduo, liberdade formal e segurança jurídica eram as palavras de ordem.

\footnotetext{
${ }^{1}$ Preleciona António Manuel Hespanha que o positivismo legalista possuía um duplo aspecto: (a) nega a existência de qualquer valor jurídico superior a lei, em relação ao qual a validade desta possa ser aferida, e (b) reduz os restantes momentos da vida jurídica a várias modalidades da mera aplicação da lei aos factos, desprovidas de qualquer legitimidade criadora ou inovadora (1982, p. 13).

${ }^{2}$ Pontua-se que tal legado espraia seus efeitos até hoje. A falta de um reexame crítico de institutos do direito positivo, notadamente no se refere à propriedade e à família, é uma realidade manifesta na atual conjuntura brasileira. Esta temática será mais detidamente analisada adiante.

${ }^{3}$ Nesta senda, discorre Luis Alberto Warat, "La realidad jurídica deviene norma, categoria del conocimiento, desvinculada de la dinámica existencial y de su intento de valoración y justificación. La realidad jurídica no es significativa, sino tan sólo la norma, que es constituyente de aquella" (2004, p. 156).
}

Revista de Direito Brasileira | São Paulo, SP | v. 17 | n. 7 | p. 125 - 140 | Mai./Ago. 2017 
Esta realidade não nos é estranha. Releva notar que o direito dogmático foi vivenciado no território nacional desde quando se incutiu a ideia de direito oficial. Ainda no Brasil-Colônia, o direito já assinalava contornos formalistas. Certamente, uma dogmática distinta de sua corrente acepção. Inaugurando a ideia de um direito oficial, o ordenamento jurídico lusitano foi transplantado para o território pátrio com características centralizadoras e formalistas, calcado em uma matriz escolástica que fortalecia a estrutura burocrático-patrimonialista que aqui se montava (WOLKMER, 2015, p. 86). Esta estrutura cravou raízes no direito brasileiro, atravessando a monarquia e o republicanismo. Com a ascensão política e econômica de São Paulo, sob a batuta do bacharelismo-liberal paulistano, a dogmática assume feição positivista-exegética influenciada pelo ecletismo de Victor Cousin e pelo positivismo de Auguste Comte - no final do século XIX.

Assemelhando-se à França, o positivismo e o racionalismo moderno repercutiram significativamente no Brasil. Ao invés do Code Civil de 1804, o Código Civil de 1916 instituía o verdadeiro direito. O discurso lógico, a crença na neutralidade e a pretensa exatidão da racionalidade jurídica, aqui, como lá, nutriu e legou falsas esperanças. Enquanto fonte de conhecimento, a dogmática jurídica tradicional revelou enormes déficits. Dada sua essência autorreferencial, a dogmática se mostrou incapaz de renovar seus preceitos sem violar sua própria lógica de reprodução, apresentando-se como um óbice ao desenvolvimento do ordenamento jurídico. $^{4}$

Inobstante, a dogmática jurídica possuiu diversas matizes com o passar dos anos. Conforme elucida Luis Alberto Warat, o processo histórico da dogmática tradicional pode ser dividido em três etapas. A primeira é marcada pelo conceitualismo dos textos legais, ou seja, na crença acerca da possibilidade de se entender o mundo unicamente por palavras, desprezando as experiências de situações concretas, isto é, a realidade relacional. Baseia-se no pressuposto de que não há direito além do ordenamento jurídico estabelecido por meio de leis validamente ditadas e vigentes. A dogmática jurídica, como já salientado, é diretamente vinculada ao positivismo, havendo a hegemonia do método exegético (WARAT, 2004, p. 154).

Como consequência deste formalismo, o direito civil passa a ser uma disciplina cujo conteúdo é a reprodução e a explicação das disposições prescritas no Código, não sendo objetos de questionamento a legitimação e a justificação deste direito. A docência do direito se resumia em comentar o Código em sua ordem, lendo os artigos e dissecando-os analiticamente. Houve o redimensionamento do papel do jurista a comentador da lei - segundo António Castanheira Neves o jurista era um geômetra e o juiz um instrumento passivo da vontade do Legislativo (2010, p. 189).

Na segunda etapa há a fixação de dogmas jurídicos. A partir dos conceitos jurídicos (extraídos dos textos legais) elaboram-se proposições, categorias e princípios. Criam-se princípios gerais, diretrizes que teoricamente ordenam o funcionamento das normas legais vigentes através de institutos e construções jurídicas. Nesta fase, a justificação procede da validez da lei e de sua assimilação lógica. Exemplo disso no direito nacional são os critérios para a superação de lacunas previstos no art. $4^{\circ}$ da antiga Lei de Introdução ao Código Civil, ainda constantes na Lei de Introdução às Normas do Direito Brasileiro.

Interessante pontuar que tais princípios gerais - utilizados como diretrizes retóricas serviam para, veladamente, introduzir critérios axiológicos na interpretação e aplicação da lei (o que contradiz a própria dogmática tradicional). Por essa razão que o ordenamento obtém um caráter de completude e de lógica. Esta lógica é fruto de uma ideologia e de uma axiologia incorporadas, às escusas, pelo direito a partir do intérprete. Observa-se também que a alteração ou substituição de um princípio no processo de interpretação permite, indiretamente, redefinir as palavras da lei (WARAT, 2004, p. 156).

\footnotetext{
${ }^{4}$ Sob a perspectiva da função social da propriedade, encontra-se uma consistente análise do constitucionalismo em: SANTOS; OLIVEIRA, 2016.
}

Revista de Direito Brasileira | São Paulo, SP | v. 17 | n. 7 | p. 125 - 140 | Mai./Ago. 2017 
Enfim, a terceira etapa da dogmática jurídica é caracterizada pela sistematização. Dá-se unidade às construções jurídicas. Estabelece-se uma série de conceitos e princípios que revelam certos traços de universalidade e invariabilidade, além de algumas presenças estruturais comuns a todos os institutos e construções jurídicas. O resultado desta etapa é o estabelecimento de uma teoria geral do direito.

A sistematização da ciência jurídica por uma teoria geral é objeto de destaque com Hans Kelsen, em sua célebre obra Teoria Pura do Direito, cujo objetivo primordial foi estabelecer categorias e bases metodológicas que permitissem compreender sistematicamente toda norma jurídica científica. Com ele, o método da dogmática jurídica foi estruturado em níveis altamente sofisticados 5 .

Partindo de uma perspectiva exclusivamente jurídica - contra o sincretismo metodológico - Hans Kelsen erige a pureza como princípio metodológico fundamental, tendente a libertar a ciência do direito de qualquer elemento extra normativo, como os fundamentos jusnaturalista, as explicações causais, os valores e o voluntarismo. "Compreender o fenômeno jurídico significava, nesse sentido, também desvinculá-lo de qualquer relação necessária com a moral ou de uma pretensão essencial de promoção da justiça" (LEAL, 2014, p. 250). Prezando pela rigorosa autonomia do direito, busca-se "evitar o sincretismo metodológico que obscurece a essência da ciência jurídica" (KELSEN, 2012, p. 2)

Do mesmo modo, é visada a neutralização de aspectos políticos e ideológicos em consideração às normas jurídicas. Para tanto, uma das idealizações do autor foi a adoção do monismo jurídico como ponto de vista. Consequência disso foi a eliminação teórica da clássica distinção entre direito público e direito privado, dado ao fato de que esta distinção provoca a intervenção da política na ciência do direito.

A doutrina kelseniana influenciou fortemente a forma de se compreender o ordenamento jurídico privado, integrando-o a uma ordem jurídica geral. Antes de Hans Kelsen existiam apenas dogmáticas particulares (direito civil, direito penal, direito administrativo etc.), sendo ele quem primeiro buscou consolidar uma compreensão geral do direito que também fosse autônoma, sistemática e unitária, a partir de princípios de uma dogmática comum do direito (WARAT, 2004, p. 74).

Para o autor, o sistema jurídico se compõe pelo conjunto de normas ordenadas escalonadamente entre si - pirâmide normativa - em cujo ápice se encontra uma norma gnosiológica (não positiva, mas suposta) e abaixo dela a Constituição que, por sua vez, é a superior entre as demais normas positivadas. A validade das normas hierarquicamente inferiores se dá na conformidade com o conteúdo e procedimento da norma superior (estática). Além disso, o ordenamento jurídico possui a qualidade de se autorreproduzir, tendo como característica essencial regular sua própria criação e aplicação (dinâmica jurídica).

O grande problema do positivismo normativista kelseniano é que, por conta da pureza metodológica, traça uma radical distinção entre o conhecimento científico do direito e o conhecimento operativo. "A pureza para Kelsen está na forma de olhar e não na coisa olhada" (WARAT, 2004, p. 72). A sintaxe lógica de Hans Kelsen depara-se com uma patente incapacidade de representação da realidade ao mesmo passo em que relega o saber jurídico para fora da ciência do direito; a prática forense desvencilha-se até mesmo da ciência, que mais se assemelha a uma metalinguagem do direito.

Ademais, crítica que também se pode fazer à dogmática jurídica em sua vertente kelseniana é que ela inviabiliza a correlação entre o ordenamento jurídico e as condições de dominação nele subjacentes, pois retira o pano de fundo político e ideológico da rede de

\footnotetext{
${ }^{5}$ Sobre o tema, esclarecedoras são as lições de Rafael Lazzarotto Simioni, segundo o qual é possível entender as motivações da teoria pura do direito a partir de três vetores de racionalidade: "a) uma crítica às concepções psicológicas e sociológicas de ciência do direito; b) a virada lingüística do neopositivismo lógico do Círculo de Viena; e c) a fundação de uma ciência genuinamente jurídica - e por isso pura - do direito" (2011, p. 123).
}

Revista de Direito Brasileira | São Paulo, SP | v. 17 | n. 7 | p. 125 - 140 | Mai./Ago. 2017 
significações jurídicas sobre as relações sociais. Sem mais estender sobre a teorização da dogmática jurídica - que não constitui o objeto central deste trabalho - é importante ter ciência de suas bases teóricas para então compreendermos de forma mais clara a existência de institutos presentes no Código Civil brasileiro e a forma pela qual usualmente são interpretados e aplicados.

Entender a mitologia por detrás do ordenamento jurídico ajuda a perceber a sociabilidade do direito e, a partir daí, a necessidade de vê-lo como espelho da sociedade, refletindo a sua variada estrutura, estratificada e diferenciada (GROSSI, 2004, p. 67). Não cabe mais ao direito civil enclausurar os fenômenos jurídicos no Código Civil, considerando-o como um sistema fechado ditado exclusivamente pelo Estado. O novo paradigma instituído com a Constituição do Brasil - em detrimento da matriz civilista liberal-individualista - busca uma fusão entre o social e o jurídico. Sem desconsiderar os pontos positivos da dogmática, o direito civil contemporâneo deve tutelar um sujeito de direito concreto.

A Constituição da República de 1988, enquanto pacto político democrático se legitima pela convivência e coexistência de concepções divergentes, diversas e participativas. Múltiplos interesses são albergados constitucionalmente evidenciando que o poder estatal não é a única e exclusiva fonte de todo o direito. Ao invés de sufocar o fenômeno jurídico que brota da sociedade, portanto, compete ao Estado criar mecanismos para que perspectivas heterogêneas possam conviver harmoniosamente, o que conduz à necessidade de descentralização da juridicidade, de real influência da participação popular, do elogio à diversidade e à tolerância. Afirmar isso é ratificar o caráter democrático do direito, em geral, e do direito civil, em particular.

\section{O DIREITO CIVIL E O CONSTITUCIONALISMO}

Conveniente mencionar de antemão que direito civil e constitucionalismo nem sempre se relacionaram diretamente. Por constitucionalismo entende-se o conjunto de doutrinas que, aproximadamente a partir da metade do século XVII, tem se dedicado a recuperar no horizonte da constituição dos modernos o aspecto de limite e de garantia (FIORAVANTI, 2011, p. 85). Certamente, as noções de limite e de garantia almejadas alteraram-se com o passar dos anos. O estágio atual do constitucionalismo é fruto de uma construção histórico-social, lapidado por inúmeras revoluções, objeto de avanços e retrocessos e que, obviamente, não está perfeito e acabado. "A Carta Política, mais do que uma obra feita, é um projeto em constante reformulação" (COELHO, 2013, p. 61).

Pode-se dizer que a aproximação entre o direito civil e a constituição, sob a perspectiva que aqui nos interessa, se deu com o crescente movimento de humanização do direito, o qual se acentuou a partir do segundo pós-guerra. No Brasil, a Constituição da República de 1988 foi o marco deste paradigma humanista. Em uma visão sistemática, a Constituição passou a ser o centro gravitacional do direito privado, alterando sua orientação, da tutela do patrimônio para a da pessoa.

Dotada de eficácia normativa e com um virtuoso rol de direitos fundamentais - núcleo essencial da Constituição - a lei suprema reconheceu as carências e particularidades dos indivíduos, conferindo proteção específica àqueles socialmente mais vulneráveis. No campo da civilística, a era dos códigos cedeu espaço para a era dos estatutos, voltada a um sujeito de direito que é identificado por suas fragilidades fáticas, enquanto consumidor, locatário, criança, idoso etc.

Mas mais uma se diga, o avanço constitucional não é um dado. Com a promulgação da Constituição em 05 de outubro de 1988 iniciaram-se os óbices à sua concreção. Desde logo, a eficácia das normas constitucionais passou a ser fonte de inúmeros debates acadêmicos e jurisprudenciais. A controvérsia acerca da programaticidade ou autoaplicabilidade imediata da 
norma constitucional é bem representada na celeuma envolvendo o $\S 3^{\circ}$ do artigo 192 da Constituição ${ }^{6}$. Objeto da ADI n. 4/DF, o aludido dispositivo foi julgado pelo Supremo Tribunal Federal como regra destituída de executoriedade imediata ${ }^{7}$.

Sem embargo, a doutrina nacional - com inspiração, sobretudo no italiano Vezio Crisafulli - ainda que reconhecendo a existência de gradações entre os efeitos das normas constitucionais, já defendia que toda norma plasmada na Constituição possuía uma eficácia mínima (inclusive as denominadas programáticas), influenciando na interpretação e integração do ordenamento jurídico, na vinculação negativa do legislador e da administração pública e na não recepção de lei anterior incompatível.

Mas isso não impediu o déficit de concretização e realização jurídico-constitucional que ainda persiste em larga escala. Sobre a temática, Marcelo Neves alerta sobre os riscos de uma constitucionalização simbólica. Para o autor, o "funcionamento hipertroficamente políticoideológico da atividade e texto constitucionais afeta os alicerces do sistema jurídico constitucional" (NEVES, 2015, p. 69). Tal fenômeno ocorre na falta de ressonância na práxis dos órgãos estatais e na conduta e expectativas da população em relação aos preceitos e instituições constitucionais básicas (direitos fundamentais, a "separação" dos poderes e a eleição democrática). A despeito de um texto constitucional simbolicamente includente vislumbra-se uma realidade constitucional excludente, o que significa dizer a existência de uma normatividade restrita.

Identificando com este caráter simbólico, é possível afirmar que, na gênese da vigência da Constituição, a aplicação das normas constitucionais nas relações privadas se deu escancaradamente tão só de forma retórica, no sentido de que, ainda que invocadas, eram inaplicáveis ao caso concreto em decorrência de ausência de legislação infraconstitucional, considerada como condição inafastável para a "plena eficácia" dos dispositivos constitucionais (TEPEDINO, 2011, p. 100).

Hoje, no que tange aos direitos fundamentais, encontra-se superado tal posicionamento pelo Supremo Tribunal Federal. A maturação dos estudos a respeito da Constituição da República de 1988 e suas potencialidades, bem como a rejeição do entendimento segundo o qual direito público e direito privado seriam opostos e incomunicáveis, levou à gradual aplicação das normas constitucionais nas relações privadas.

Importante consignar que a imprescindibilidade da constitucionalização do direito privado é proporcional à discrepância existente entre a realidade social e o mandamento constitucional. Como salienta Daniel Sarmento:

A sociedade brasileira é profundamente injusta, e as relações privadas que nela se travam são permeadas pela assimetria e opressão. A violação dos direitos humanos, neste quadro, não provém apenas do Estado e dos seus agentes, mas de múltiplos atores, presentes em cenários variados como a família, a empresa, o mercado e a sociedade civil (2003, p. 297).

Apesar desta certeza, o preciso grau de eficácia das normas constitucionais nas relações privadas, mormente no que se refere a direitos fundamentais - eficácia horizontal - é uma das grandes incógnitas do direito civil contemporâneo, haja vista que a autodeterminação do

\footnotetext{
${ }^{6}$ Literalmente: “As taxas de juros reais, nelas incluídas comissões e quaisquer outras remunerações direta ou indiretamente referidas à concessão de crédito, não poderão ser superiores a doze por cento ao ano; a cobrança acima deste limite será conceituada como crime de usura, punido, em todas as suas modalidades, nos termos que a lei determinar". A Emenda Constitucional n. 40/2003 suprimiu o transcrito parágrafo.

${ }^{7}$ Observa Daniel Sarmento que: "a negativa de eficácia a certas partes da Constituição não resulta apenas de resistência ideológica. A esta se agregam razões jurídicas ponderáveis, como o grau de indeterminação semântica de algumas normas, assim como o fato de que a aplicação de outras depende da utilização de recursos escassos, bem como da formulação de políticas públicas, e não de um mero comportamento absenteísta do Estado" (2003, p. 275).
}

Revista de Direito Brasileira | São Paulo, SP | v. 17 | n. 7 | p. 125 - 140 | Mai./Ago. 2017 
indivíduo também é resguardada constitucionalmente. Várias são as teorias que versam sobre a temática. Dentre elas, são as mais difundidas: (a) doutrina da "state action"; (b) teoria da eficácia indireta e mediata; e (c) teoria da eficácia direta e imediata. Com a pretensão única de propiciar uma breve ideia do que trata as referidas teorias, serão destacadas algumas de suas características gerais.

Teoria prevalecente nos Estados Unidos da América, a doutrina da state action prega que, em regra, os direitos fundamentais vinculam apenas o setor público, não conferindo direito subjetivo às relações privadas. Como exceção, além de alguns precedentes promanados pela Suprema Corte $^{8}$, tem-se a $13^{a}$ Emenda da Constituição americana, responsável pela abolição da escravatura. Relevante contextualizar que tal matriz teórica é plenamente justificável ante a tradição liberal estadunidense e ao seu forte federalismo, que atribui competência aos estados federados para legislar sobre direito privado. De toda forma, "ela não foi capaz de construir standards minimamente seguros e confiáveis na jurisdição constitucional norte-americana" (SARMENTO; GOMES, 2011, p. 63).

A teoria da eficácia indireta e mediata, ao seu turno, foi desenvolvida em solo germânico, onde é a concepção dominante. Como o próprio nome sugere, a eficácia das normas constitucionais na esfera privada, por esta teoria, se dá de forma oblíqua, não sendo diretamente oponível entre particulares. $\mathrm{O}$ direito à autonomia privada é seriamente defendido, até mesmo a despeito de direitos fundamentais, mas não de forma absoluta.

A conciliação entre direitos privados e direitos fundamentais dá-se pela influência destes nas relações privadas que é intermediada pelo próprio material normativo do direito privado. Para tanto é pressuposta "uma concepção de direitos fundamentais como um sistema de valores com a existência de portas de entrada desses valores no próprio direito privado, que seriam as cláusulas gerais" (SILVA, 2005, p. 76). Isto é, a indeterminação semântica da legislação cível ou sua lacuna deve ser preenchida substancialmente pelo axioma constitucional. Competiria ao Judiciário, deste modo, preencher as cláusulas indeterminadas a partir dos direitos fundamentais, bem como declarar a inconstitucionalidade de normas confrontantes com tais direitos. A aplicação direta dos direitos fundamentais é hipótese excepcionalíssima em litígios privados.

Finalmente, tem-se a teoria da eficácia direta e imediata. Esta teoria, também de origem alemã, é a de maior prestígio entre os juristas brasileiros. Reza tal constructo teórico que os direitos fundamentais devem ser aplicados diretamente nas relações privadas, independentemente de mediação legislativa, revestindo-se de oponibilidade erga omnes (SARMENTO; GOMES, 2011, p. 71). Oportuno advertir que os adeptos da teoria da eficácia imediata dos direitos fundamentais nas relações privadas não defendem a indiscriminada incidência destes direitos. $\mathrm{O}$ que se defende com rigor é a necessidade de se relevar o direito fundamental em jogo com a autonomia privada dos particulares em consideração ao caso concreto. Ao revés do que bradam seus opositores, não se trata de uma doutrina radical, que "possa conduzir a resultados liberticidas [...], pois ela não prega a desconsideração da liberdade individual no tráfico jurídico-privado, mas antes impõe que seja devidamente sopesada na análise de cada situação concreta" (SARMENTO; GOMES, 2011, p. 72).

Aparenta ser nesse sentido a incisiva lição de Pietro Perlingieri, para quem "a norma constitucional pode, também sozinha (quando não existirem normas ordinárias que disciplinem a fattispecie em consideração), ser a fonte da disciplina de uma relação jurídica de Direito Civil" (PERLINGIERI, 2006, p. 11). Esta postura vai de encontro à difundida noção de força normativa da Constituição, desenvolvida em autores como Konrad Hesse e José Joaquim Gomes Canotilho.

O Supremo Tribunal Federal em diversos casos sinalizou entendimento favorável à eficácia direta dos direitos fundamentais nas relações privadas ${ }^{9}$, há inclusive votos que enfrentam

\footnotetext{
${ }^{8}$ Vide, por exemplo: Marsh v. Alabama (326 U.S. 501 - 1946); Caso Shelley v. Kraemer (334 U.S. 1 - 1948).

${ }^{9}$ Vide STF, $2^{\mathrm{a}}$ T., RE 160.222, Rel. Min. Sepúlveda Pertence, publ. em 01/09/1995; STF, $2^{\mathrm{a}}$ T., RE 158.215, Rel. Min. Marco Aurélio, publ. em 07/06/1996; STF, 2 ${ }^{\mathrm{a}}$ T., RE 161.243, Rel. Min. Sydney Sanches, publ. em 12/11/1996.

Revista de Direito Brasileira | São Paulo, SP | v. 17 | n. 7 | p. 125 - 140 | Mai./Ago. 2017
} 
frontalmente esta temática ${ }^{10}$. Entretanto, não pode se afirmar que esta seja a posição da Corte. Além do fato de esta teoria não ter sido expressamente reconhecida pela maioria dos ministros do Supremo Tribunal Federal, há casos que versam precisamente sobre esta problemática em que tal questão indevidamente sequer foi ventilada ${ }^{11}$. A dúvida que fica, deste modo, é se a Corte tem certa inclinação em prol da aplicabilidade direta e imediata dos direitos fundamentais nas relações privadas ou se tal teoria é utilizada pelos ministros de forma "ad hoc", como mero argumento de autoridade.

Neste sentido o relatório da pesquisa Processo Legislativo e Controle de Constitucionalidade: as fronteiras entre direito e política, realizada para a Secretaria de Assuntos Legislativos do Ministério da Justiça no contexto do Projeto Pensando o Direito, sob a coordenação de José Rodrigo Rodriguez e Marcos Nobre:

Em suma, nos casos analisados, os Ministros do STF podem servir-se de toda sorte de argumentos para fundamentar suas respectivas decisões. Não há propriamente um padrão decisório, pois um ou mais tipos de argumentos podem ser utilizados num mesmo voto, indistintamente. Se algum padrão houver, ele não poderá ser descrito de outra forma, senão como um mosaico de argumentos de tipos diversos, dos quais são exemplos aqueles apontados na pesquisa: os argumentos que recorrem a uma interpretação sistematizada da lei e dos princípios de direito e os que lançam mão da doutrina, da jurisprudência ou da opinião de especialistas de áreas não jurídicas. Esse elenco de possibilidades admite tanto os votos que se fundam em somente um argumento, como aqueles que lançam mão de mais de um, sendo mesmo possível que, utilizando suas palavras como argumento de autoridade, Ministros citem a si próprios, seja referindo-se aos textos acadêmicos que escreveram, seja aos votos que proferiram em julgamentos anteriores, seja a ambos. Nessas condições, a técnica jurídica pode ser utilizada como elemento de legitimação, para dar à decisão arbitrária a aparência de decisão fundamentada. Sobretudo graças aos argumentos de autoridade, a decisão judicial não assumiu, nos casos estudados, nem o caráter de um campo de disputa pelo sentido das normas, nem o caráter de um espaço para decisões em nome de uma verdade inquestionável, mas sim o caráter de algo que busca assegurar uma determinada aparência, fazendo ter feição justa e legal aquilo que cada Ministro, em seu voto, considera justo e legal $(2010$, p. 78$)$

Diante destas características do constitucionalismo brasileiro, tem-se como indicativo a real necessidade de superação da tradicional dogmática civil. A Constituição da República de 1988 propôs uma mudança de paradigma, uma renovação da ordem jurídica. A abertura axiológica proposta constitucionalmente, contudo, ainda não ressoou plenamente na seara jurídico-civil, tampouco na realidade social.

Impende mencionar que a importância da vigente Constituição não se dá pelo simples fato de ser $a$ Constituição, não é ela um fim em si mesmo. Por sua carga valorativa, por seu projeto social é que a Constituição deve ser defendida com afinco, devendo substancializar a porosidade de um direito civil que nunca será capaz de abarcar a totalidade das relações jurídicas. Alinha-se aqui à doutrina de Pietro Perlingieri, para quem:

è vero il testo costituzionale non contiene le chiavi di ogni verità. Tuttavia il costituzionalismo può assolvere il ruolo di garanzia soltanto se si riconosce que contenutisticamente i suoi princípi hanno rilevanza normativa e sono idonei a

\footnotetext{
${ }^{10}$ Vide voto de lavra do Ministro Celso de Mello, no julgamento da $2^{\mathrm{a}}$ T. no RE 201.819-8, de relatoria do Min. Gilmar Mendes, publ. em 21/10/2005.

${ }^{11}$ Por exemplo: STF, Tribunal Pleno, RE 407.688, Rel. Min. Cezar Peluso, publ. em 03/03/2006.
} 
rappresentare i valori che connotano la società che si vuole garantire: personalismo, pluralismo, solitarismo ecc. (PERLINGIERI, 2014, p. 7).

Valendo-se destes valores é que devemos repensar o direito civil contemporâneo, a fim de que seja aberto e plural, dialógico no método e dialético em sua substância, para que receba os influxos da democracia e, "à luz do paradigma pedagógico emancipatório do saber e do ensino jurídico, alavanca seu fomento em perfis que decodificam o presente, denunciam o ultrapassado e arrostam o porvir em diálogos interdisciplinares" (FACHIN, 2002, p. 42).

É inegável a existência de inúmeros avanços. Mas o desenvolvimento do direito civil ainda se encontra aquém do desejável sob a ótica constitucional. Versando sobre o atraso metodológico do direito administrativo italiano, Sabino Cassese acentua que a persistência do método tradicional do estudo do direito acarreta um esvaziamento parcial da ordem interna ${ }^{12}$. $\mathrm{O}$ problema identificado pelo autor se assemelha com o qual nos defrontamos, a civilística brasileira ainda não está integralmente adaptada. As perplexidades do direito civil contemporâneo têm de ser enfrentadas.

\section{PERPLEXIDADES, VEREDAS E OPORTUNIDADES}

O senso comum teórico dos juristas, denunciado por Luis Alberto Warat, é uma das perplexidades que se pretende pontuar. Designa o autor como senso comum teórico as condições implícitas de produção, circulação e consumo de verdades jurídicas - sacralizadas sob o álibi da "racionalidade científica" - presentes em diferentes práticas de enunciação e escritura do direito (WARAT, 1987, p. 57). Em outras palavras, trata-se da aceitação inquestionada de obviedades e verdades, principalmente da dogmática jurídica, que se solidificam na praxe forense a despeito de toda a base retórico-ideológica que a constitui. Anota o autor que:

os juristas contam com um emaranhado de costumes intelectuais que são aceitos como verdades de princípio para ocultar o componente político da investigação de verdades. Por conseguinte se canonizam certas imagens e crenças para preservar o segredo que esconde as verdades. O SCTJ [senso comum teórico dos juristas] é o lugar do secreto. As representações que o integram pulverizam nossa compreensão do fato de que a história das verdades jurídicas é inseparável (até o momento) da história da repressão burguesa (WARAT, 1987, p. 59).

Isso permite à trajetória epistemológica tradicional conceber o mundo social como sendo um sistema de regularidades objetivas e independentes. Mas isso não passa de uma ficção, uma construção que sugere a coisificação das relações sociais. E o "conhecimento, na medida em que é purificado pela razão, limita maldosamente a percepção dos efeitos políticos das verdades" (WARAT, 2004, p. 156). Patente esta violência simbólica, impreterível é a extração do sentido político da normatividade que a epistemologia clássica reveste indevidamente de cientificidade. Propõe o autor, então, uma posição revisionista dos valores epistemológicos que regulam o processo de constituição das verdades jurídicas consagradas.

No âmbito do direito civil, a crítica waratiana evidencia a necessidade de se questionar o discurso dos institutos e das normas civis. Esta é uma prática que tem de ser aperfeiçoada e difundida, e, no entanto, pouca atenção recebe. Ainda vivemos em um universo de abstrações normativas. O legado positivista ainda está longe de ser superado por completo. A predominância da dogmática tradicional na concepção de ordenamento jurídico é uma realidade inquestionável.

\footnotetext{
${ }^{12}$ Assevera o autor: "che il metodo tradizionale di studio del diritto persista in Italia, ma a prezzo di um suo parziale svuotamento dall'interno. Il sorriso del gatto rimane ed è visivile, dopo che il gatto del Cheshire se n'è andato" (2010, p. 516).
}

Revista de Direito Brasileira | São Paulo, SP | v. 17 | n. 7 | p. 125 - 140 | Mai./Ago. 2017 
Isto é verificável diante da falta de uma tradição epistemológica e na corriqueira resignação irrefletida para com o dispositivo legal por parte dos profissionais do direito. Entretanto, "as mitologias, que tiveram um papel fundamental no projeto jurídico burguês, não conseguem se manter em pé diante das necessidades e das solicitações da sociedade contemporânea" (GROSSI, 2004, p. 96).

Por certo que o direito não pode abdicar da sua dimensão formal, mas tem de estar voltado a uma história vivente. Paolo Grossi destaca que cabe ao direito tratar de categorias ordenantes que pescam na realidade, e não só flutuam sobre o real, como acontece com todo fenômeno autenticamente e não ficticiamente ordenante. A legalidade dos códigos, neste sentido, não deve se desassociar do mandamento constitucional, pois é nele que constam os valores que orientam os costumes e o desenvolvimento das realidades econômicas e das ordens sociais.

Ao que parece, também é nesta direção que caminham os ensinamentos de Pietro Perlingieri ao defender que "il pluralismo culturale e ideologico che si rinnova, anche a prescindere dalle trattazioni ufficiali o dal pensiero consolidato, comunica la sua forza vitale all'ordinamento, contribuendo a rinnovarlo" (PERLINGIERI, 2014, p. 4). Baseado no magistério de Pasquale Femia, Pietro Perlingieri destaca a importância do valor jurídico (que não se confunde com a lei):

$i$ valori giuridici sono ciò che indica il sistema ordinamentale, quale articulato $e$ complesso insieme di fonti costituenti la totalità dell'esperienza sócio-culturale. Il valore non si riduce mai a norma esclusiva ma contribuisce a cogliere - nella norma um momento (necessariamente) parziale - dela sua potenzialità trasformatrice, consentendo di sviluppare una ragionevole argomentazione giuridica (PERLINGIERI, 2014, p. 4).

Em direção oposta, a influência da hermenêutica positivista cria uma barreira entre a norma jurídica e a realidade fática e sua historicidade, gerando um ambiente propício a anacronismos. Os institutos jurídicos, sob esta ótica, prescindem de justificação, contextualização e adequação social, asfixiando os valores que emergem da sociedade e tapando os olhos para as transformações sociais. Este nefasto quadro pintado pelo positivismo demonstra a indispensabilidade de se pontificar uma relação entre os institutos jurídicos civis e sua relevância histórico-social, o que permite a adequada manutenção, reconstrução ou superação de tais institutos.

É com pesar que se depreende que o formalismo ainda não foi superado. E ao afirmar isso, alinha-se ao entendimento de José Rodrigo Rodriguez para quem formalismo pode significar: (a) a visão do direito estruturada na aplicação mecânica (lógico-formal) do direito positivo, como no caso da subsunção do caso concreto à lei (legalismo); (b) como também o raciocínio pautado em categorias jurídicas, dotadas de verdade, transcendentes ao direito positivo, seja em razão de seu enraizamento e historicidade, seja em função de seu valor lógico ou racional, implicando, em ambos os casos, na naturalização das categorias dogmáticas (absolutismo conceitual). A impressão que se tem de uma mudança radical na aplicação do direito em contraponto ao formalismo, talvez possa ser atribuída à superação do formalismo legalista (cada vez mais raro), o absolutismo conceitual que, contudo, é muito comum no Brasil (2010, p. 162). Não é à toa que mitologias como completude, coesão e autossuficiência, assim como postulados de ordem, certeza e estabilidade ainda subsistem.

Portanto, "resta criar meios de adequar a norma às transformações sociais, [...] identificando o arcabouço ideológico que subjaz à norma, a mentalidade que a construiu, seja coletiva ou criada por um pequeno grupo social" (BANHOZ; FACHIN, 2002, p. 73). O reexame crítico de institutos do direito positivo deve condizer não só com os valores sociais - que encontram respaldo constitucionalmente - mas também com as especificidades da realidade 
contemporânea, como, por exemplo, uma economia global, os avanços tecnológicos e o engrandecimento dos direitos humanos.

Identificar a norma jurídica se baseando unicamente no rigor formal de sua edição, que a caracterizaria como ato válido por ser promanado pelo soberano, neste contexto, figura como um equívoco. O mesmo se pode dizer do caráter estatizante do direito civil. Uma visão aberta do ordenamento jurídico deve se guiar antes pelo conteúdo da norma e por sua conformação social.

O autoritarismo do monopólio da juridicidade pelo Estado deforma até mesmo a noção de direito. A dimensão de potestade do direito assume um caráter patológico ao reduzir ao poder estatal a forma de identificação do fenômeno jurídico, fazendo com que seja esquecida a autenticidade fisiológica do fenômeno jurídico e deturpando sua essência. A fisiologia do jurídico, como sublinha Paolo Grossi, "deve ser intimamente compenetrada com a fisiologia da sociedade" (2004, p. 65). O direito não é apenas o instrumento coercitivo do soberano. Antes de ser poder, norma e sistema de categorias formais, o direito é experiência, uma dimensão da vida social.

Atinente à juridicidade para além do Estado, interessante movimento é debatido na Europa. Ante uma crise de unidade e soberania estatal, ganha importância a concepção de uma ordem ultranacional constituída em rede (e não de forma piramidal, em que se acentua a existência de relações hierarquizadas). Reconhecendo as interações heterogêneas e complexas existentes em sociedade, os Estados passam a cooperar entre si. Como consequência, abandonase o paradigma de unidade estatal e de um ordenamento fechado e definido (Cf.: PREDIERI; MORISI, 2001).

Com as devidas ressalvas, lições podem ser retiradas desta realidade europeia, pois pensar o direito civil fora do atual estágio do constitucionalismo brasileiro talvez nos seja uma realidade não tão distante. Os desafios trazidos pela globalização não cessam, sendo plenamente justificável uma maximização da cooperação internacional e uma flexibilização da normatividade estatal.

Mas sem ir tão longe quanto à transposição de fronteiras territoriais, um promissor ponto de análise do direito civil é a interdisciplinaridade. O direito civil pensado exclusivamente pelo jurista padece do mal de uma visão unidimencionada. Se é constante a interação entre os vários ramos do direito entre si e entre o direito e outros ramos do saber - como a filosofia, a sociologia, a política, a economia, etc. - é salutar que haja um efetivo diálogo entre estas disciplinas. "A pluralidade afasta a unidade conceitual arbitrária" (FACHIN, 2000, p. 247).

A interdisciplinaridade, impende advertir, não significa a perda da singularidade do direito civil - algo que acabaria por descaracterizá-lo -, nem mesmo a perda da autonomia problemática do direito, mas a assimilação e consideração de fatores sociais que são estranhos à ciência jurídica como forma de aperfeiçoamento do sistema jurídico. Nos dizeres de Luiz Edson Fachin, necessário se faz um novo mapeamento do direito civil, "cuja descrição não pode ser previamente construída nem se deve antecipar à emolduração do objeto ainda em curso" (FACHIN, 2000, p. 322).

A imbricação entre o direito e a economia evidencia as possibilidades que podem advir da interdisciplinaridade do direito civil. O profícuo diálogo entre o direito e a economia é o que amplia a visão do direito em relação aos comportamentos e análises econômicas, ajudando-o a compreender a competição em mercados, isso é o que torna possível uma regulação da concorrência em prol da sociedade (sem com isso inviabilizar a atividade empresarial). Os frutos desta relação podem superar as expectativas, haja vista que uma avaliação ou análise econômica na formulação e aplicação de normas jurídicas é capaz de torná-las mais eficientes ${ }^{13}$, até porque há um interesse comum entre estas áreas do conhecimento, por exemplo, em matérias como propriedade, contratos e responsabilidade civil. Sem que se caia em um pragmatismo econômico,

\footnotetext{
13 "As we understand it, this approach to the law posits that legal rules are best analyzed and understood in light of standard economic principles" (Cf: JOLLS; SUNSTEIN, 1988, p. 1473).
}

Revista de Direito Brasileira | São Paulo, SP | v. 17 | n. 7 | p. 125 - 140 | Mai./Ago. 2017 
sob o aspecto metodológico, o olhar empírico das escolas de economia torna mais presente a realidade social, elidindo um mundo jurídico meramente abstrato.

Retomando à necessidade de superação da dogmática jurídica tradicional, é importante tecer algumas alertas. Ainda que se defenda que a aplicabilidade da lei pela dogmática pode conduzir a iniquidades, e o processo hermenêutico silogístico (subsunção) não é suficiente diante da porosidade do direito, a reação contra o positivismo não pode se dar a descrédito da lei - em detrimento da segurança jurídica - e do caráter democrático da produção do direito privado.

Em contraponto ao positivismo surgiram diversas correntes, como o movimento do direito livre, a jurisprudência dos interesses e a jurisprudência dos valores. Em comum, estas concepções propiciaram uma ascensão da discricionariedade judicial. Tal encaminhamento, contudo, parece não ser uma solução adequada perante o atual modelo constitucional brasileiro. Tão ruim quanto ser refém da lei é ficar à mercê da subjetividade dos magistrados.

Esta é uma das grandes problemáticas contemporâneas. $\mathrm{O}$ direito civil depende de uma metodologia segura e condizente aos desafios da atualidade. O como fazê-lo, contudo, ainda carece de resposta. Porém uma coisa é certa, tem de se engendrar um direito civil que seja instrumento da solidariedade social sem esgarçar o valor do individualismo. Esta é a tênue relação que deve permear os direitos fundamentais e a autonomia privada. Neste enveredar deve seguir o direito civil constitucional, considerando que a concreção da Constituição e dos direitos fundamentais não se dá pela aplicação cega e indiscriminada da literalidade dos incisos do artigo $5^{\circ}$. Os direitos fundamentais só serão alcançados se em consonância com os fundamentos do direito.

Libertando-se das mazelas da dogmática jurídica tradicional - que não deve ser transplantada para o plano constitucional - os direitos fundamentais devem ser abarcados pelo direito civil como norma, mas também enquanto ideologia que é, através da busca pela igualdade que reconhece as desigualdades, mirando o passado sem deixar de se atentar ao outro que está ao lado e a um futuro melhor.

\section{CONCLUSÃO}

Nas linhas pregressas se tencionou esclarecer algumas das mitologias da modernidade e evidenciar a necessidade de lermos a ordem jurídica e o direito civil de forma adequada ao constitucionalismo contemporâneo e à sua abertura axiológica. As perplexidades que daí exsurgem, como visto, não são poucas, mas a experiência revela-se como uma profícua fonte de aprendizado. A modernidade almejou uma inovadora forma de se conceber o direito, partindo de uma ordem jurídica livre de ambivalências, repleta de claridade, certeza e transparência. Como condição cultural, contudo, a modernidade não levou em conta o outro, negando a alteridade e construindo idealizações ficticiamente fora da história.

O constitucionalismo talvez seja a melhor esperança de superação da modernidade jurídica e seus equívocos, pois erige uma visão de mundo que integra o outro - não o tratando como mera abstração e simulacro persuasivo. Os ideais e valores da Constituição da República de 1988 trazem novos ares à ordem jurídica, colorindo com belas cores o futuro.

O direito civil, todavia, ainda não tirou o pé da modernidade e, até certo ponto, de seu racionalismo dogmático, sendo ainda seduzido por promessas irrealizáveis de um direito de certezas e objetividades conceituais. Contra esta herança de um direito civil pautado em teatralidades devemos nos insurgir, em prestígio de uma concepção de direito aberta, plural e voltada às condições reais da vida cotidiana.

Apenas reconhecendo a ideologia que marcou o modo de se conceber o direito privado modernamente é que se pode romper com a tradição da dogmática tradicional e seu ideal absolutamente estatizante dos fenômenos jurídicos. Esse conhecimento é libertador, fragmentando lugares-comuns e ressaltando as aporias do discurso jurídico. Desvelados os 
aspectos ideológicos, torna-se patente o caráter impreterível da aproximação entre o direito e a sociedade, sob o risco de que o direito se perca em seu formalismo, desvirtuando a relação entre fins e meios, subvertendo a integração entre teoria e prática.

Neste paradigma aberto, plural e democrático é que deve se situar a forma de se compreender o ordenamento jurídico que, renovado pela ideologia constitucional, possui condições de estar em fina sintonia com os anseios sociais. É de suma relevância uma nova tônica à noção de juridicidade, tendo em conta que é que no interior da história construída por homens - com seus idealismo e desejos, com suas virtudes e misérias - que se coloca o direito.

$\mathrm{O}$ relacionamento entre o constitucionalismo brasileiro e o direito civil já mostrou significativo avanço desde o advento da Constituição da República de 1988, mas ainda há muito a caminhar em prol de um modelo de direito civil-constitucional mais efetivo que, por condizer à realidade social, pode transformá-la, em que autonomia privada e direitos fundamentais coexistam harmoniosamente.

Os direitos fundamentais, por traduzirem a essência da Constituição em sua matriz humanista, devem substanciar a hermenêutica civilista. Em que pesem os percalços na eficácia e efetivação de tais direitos, que evidenciam o quanto ainda temos a progredir, ao contrastarmos passado e presente o porvir se pinta belo. Os reflexos de uma concepção ordenamental em consonância com o sistema de direitos fundamentais e o constitucionalismo contemporâneo já são vislumbrados; suas potencialidades, entretanto, vão muito além da atual conjuntura do direito civil.

Pensar criticamente alguns aspectos do direito civil e do direito constitucional é o que se almejou neste trabalho. Pensar criticamente o direito é o que se defende com veemência como condição para a emancipação do indivíduo. Como é perceptível ao longo de todo o texto, não são poucas as perplexidades que se apresentam. As possibilidades para uma nova civilística, todavia, são incomensuráveis. Ideias transformadoras são, sempre, bem-vindas.

\section{REFERÊNCIAS BIBLIOGRÁFICAS}

CANOTILHO, José Joaquim Gomes et al. (Org.). Comentários à Constituição do Brasil. São Paulo: Saraiva/Almedina, 2013.

CASSESE, Sabino. Il diritto amministrativo: storia e prospettive. Giuffrè, 2010.

FACHIN, Luiz Edson. Teoria crítica do direito civil. Rio de Janeiro: Renovar, 2008.

FIORAVANTI, Maurizio. Constitución: de la antigüedad a nuestros días. Tradução: Manuel Martínez Neira. Madrid: Trotta, 2011.

GROSSI, Paolo. Mitologias jurídicas da modernidade. Tradução: Arno Dal Ri Júnior. Florianópolis: Boiteux, 2004.

O direito entre poder e ordenamento. Tradução: Arno Dal Ri Júnior. Belo Horizonte: Del Rey, 2010.

HESPANHA, António Manuel. História das instituições: épocas medieval e moderna. Coimbra: Almedina, 1982. 
JOLLS, Christine; SUNSTEIN, Cass; THALER, Richard. A Behavioral Approach to Law and Economics. Stanford Law Review, Stanford, v. 50, p. 1471-1548, mai./1988.

KELSEN, Hans. Teoria pura do direito. Tradução de João Baptista Machado. São Paulo: Martins Fontes, 2012.

LEAL, Fernando. O formalista expiatório: leituras impuras de Kelsen no Brasil. Revista Direito $G V$, São Paulo, n. 19, p. 245-269, jan./jun. 2014.

LOSANO, Mario. Sistema e estrutura no direito: das origens à escola histórica (v. 1). Tradução: Carlo Alberto Dastoli. São Paulo: Martins Fontes, 2008.

LÖWY, Michael. As aventuras de Karl Marx contra o Barão de Münchhausen: marxismo e positivismo na sociologia do conhecimento. Tradução: Juarez Guimarães; Suzanne Felicie Léwy. 7. ed. São Paulo: Cortez, 2000.

NEVES, António Castanheira. Digesta: escritos acerca do direito, do pensamento jurídico, da sua metodologia e outros. Coimbra: Coimbra, 2010.

PERLINGIERI, Pietro. I valori e il sistema ordinamentale "aperto". Civilistica.com, Rio de Janeiro, a. 3, n. 1, jan./jun. 2014. Disponível em: <www.civilistica.com>. Acesso em 06/01/2016.

Perfis de Direito Civil: uma Introdução ao Direito Civil-Constitucional. Tradução: Maria Cristina de Cicco. Rio de Janeiro: Renovar, 2006.

RAMOS, Carmem Lucia Silveira et al. (Org.). Diálogos sobre Direito Civil: construindo uma racionalidade contemporânea. Rio de Janeiro: Renovar, 2002.

RODRIGUEZ, José Rodrigo; COSTA, Carlos Eduardo Batalha da Silva e; BARBOSA, Samuel Rodrigues (Orgs.). Nas fronteiras do formalismo: A função social da dogmática jurídica hoje. São Paulo: Saraiva, 2010.

; NOBRE, Marcos (Coords.). Processo legislativo e controle de constitucionalidade: as fronteiras entre direito e política (relatório de pesquisa). Brasília: Secretaria de Assuntos Legislativos do Ministério da Justiça do Brasil, 2010.

SANTOS, Leonardo Caixeta; OLIVEIRA, Leandro Corrêa. A função social da propriedade imobiliária nas constituições republicanas brasileiras: da estrutura à função. São Paulo, Revista de Direito Brasileira, v. 14, n. 6, p. 109-127, mai./ago. 2016.

SARMENTO, Daniel. A normatividade da Constituição e a constitucionalização do direito privado. Revista da EMERJ, Rio de Janeiro, v. 6, n. 23, p. 272-297, 2003.

; GOMES, Fábio Rodrigues. A eficácia dos direitos fundamentais nas relações entre particulares: o caso das relações de trabalho. Revista TST, Brasília, v. 77, n. 4, p. 60-102, out./dez. 2011. 
SCHWARTZ, Germano; SANTOS NETO, Arnaldo Bastos. O sistema jurídico em Kelsen e Luhmann: diferenças e semelhanças. Direitos Fundamentais \& Justiça, n. 4, jul./set. 2008.

SILVA, Virgílio Afonso da. A constitucionalização do direito: os direitos fundamentais nas relações entre particulares. São Paulo: Malheiros, 2005.

SIMIONI, Rafael Lazzarotto. A teoria pura do direito de Kelsen e a sintaxe linguística no neopositivismo lógico do Círculo de Viena. Novos Direitos, n. 2, p. 121-246, 2011.

TEPEDINO, Gustavo. Normas constitucionais e relações privadas na experiência das cortes superiores brasileiras. Revistas TST, Brasília, v. 77, n. 3, p. 98-110, jul./set. 2011.

WARAT, Luis Alberto. As vozes incógnitas das verdades jurídicas. Tradução: Horácio Wanderlei Rodrigues. Sequência, Florianópolis, v. 8, n. 14, p. 57-61, 1987.

Epistemologia e ensino do direito: o sonho acabou. Coordenadores: Oribes Mezzaroba; Arno Dal Ri Júnior; Aires José Rover; Cláudia Servilha Monteiro. Florianópolis: Boiteux, 2004.

WOLKMER, Antonio Carlos. História do direito no Brasil. 8. ed. Rio de Janeiro: Forense, 2015. 